\title{
Primary pyomyositis caused by ca-MRSA
}

\author{
Bruce M. Lo • Benjamin A. Fickenscher
}

Received: 16 April 2008 / Accepted: 10 September 2008/ Published online: 17 October 2008

(C) Springer-Verlag London Ltd 2008

A 22-year-old male with sickle-cell trait presented with a 1week history of progressive pain and swelling in his left posterior thigh. He denied any trauma, fever, travel outside of the United States, or intravenous drug usage. On examination, he was afebrile at $36.8^{\circ} \mathrm{C}\left(98.3{ }^{\circ} \mathrm{F}\right)$ with stable vital signs. His examination was significant for exquisite tenderness, erythema, induration, and swelling of the posterior thigh (Fig. 1). A computed tomography scan of the extremity was obtained that showed a $5.5 \mathrm{~cm} \times 4.4$ $\mathrm{cm} \times 20-\mathrm{cm}$ fluid collection within the biceps femoris muscle (Fig. 2). The patient underwent open drainage of the abscess and was placed on linezolid. Wound and blood cultures were consistent with community-associated methicillin-resistant Staphylococcus aureus (ca-MRSA).

Pyomyositis is an acute bacterial infection of the muscles characterized by subacute abscess formation. While pyomyositis is rare in temperate climates, the incidence has been increasing, with the majority having comorbidities

B. M. Lo $(\bowtie) \cdot$ B. A. Fickenscher Department of Emergency Medicine, Eastern Virginia Medical School,

Raleigh Building, 600 Gesham Drive, Room 304,

Norfolk, VA 23507, USA

e-mail: brucelo1@yahoo.com

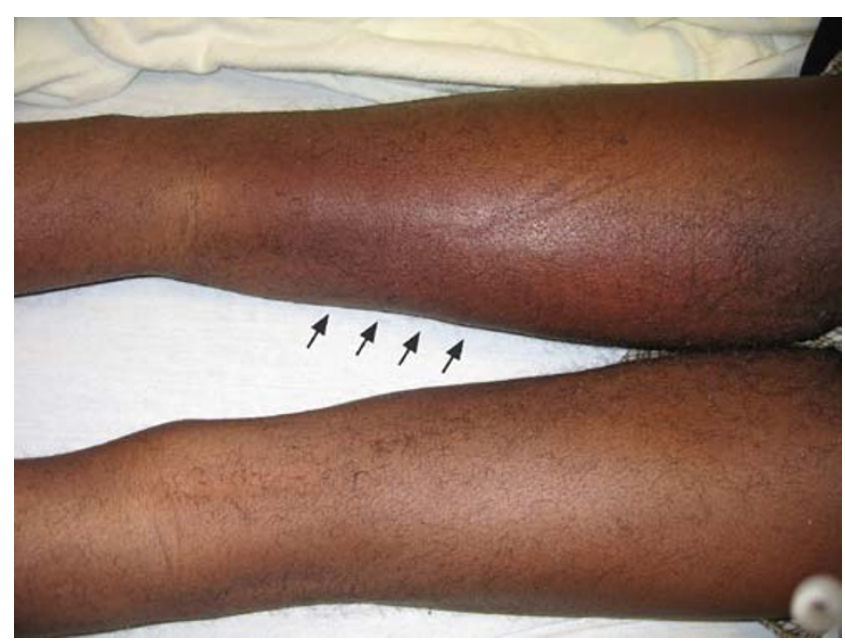

Fig. 1 Erythema and swelling of posterior thigh (arrows)

causing an immunocompromised state, such as HIV and diabetes [1]. Sickle-cell disease has also been implicated as a risk factor for developing pyomyositis [2-4].

Staphylococcus aureus has been implicated in the majority of cases [1], and recently, ca-MRSA has been found to be an important causative agent in pyomyositis $[5,6]$. Because of the rarity of pyomyositis in temperate climates, the diagnosis can be difficult to make, and the patient's symptoms and exam can easily be mistaken for other diagnoses, such as 


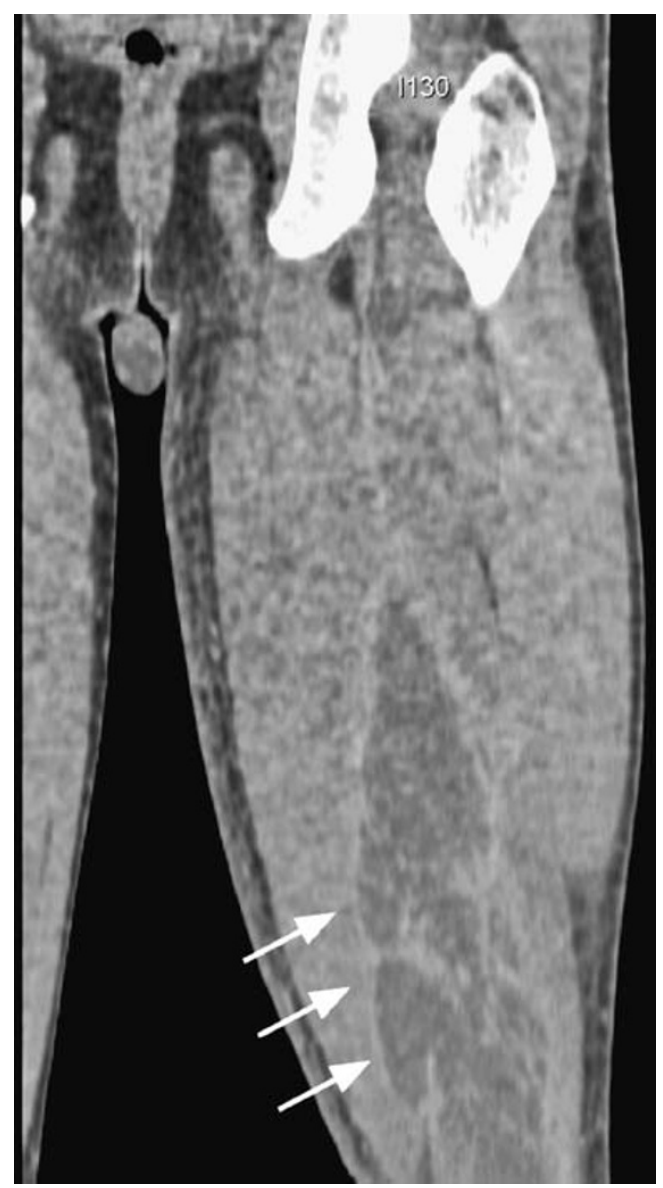

cellulites [7]. Physicians should consider pyomyositis in patients with severe muscle tenderness in areas of apparent cellulitis and recognize ca-MRSA as an emerging cause of this potentially devastating disease.

\section{References}

1. Crum NF (2004) Bacterial pyomyositis in the United States. Am J Med 117:420-28

2. Millar C, Page T, Paterson P (2001) MRSA pyomyositis complicating sickle cell anaemia. Clin Lab Haematol 23:329-32

3. Akman I, Ostrov B, Varma BK et al (1996) Pyomyositis: report of three patients and review of the literature. Clin Pediatr 35:397-401

4. Konnur N, Boris JD, Nield LS et al (2007) Non-tropical pyomyositis in pediatric and adult patients. W V Med J 103:22-3

5. Ruiz ME, Yohannes S, Wladyka CG (2005) Pyomyositis caused by methicillin-resistant Staphylococcus aureus. N Engl J Med 352:1488-9

6. Pannaraj PS, Hulten KG, Gonzalez BE et al (2006) Infective pyomyositis and myositis in children in the era of communityacquired, methicillin-resistant Staphylococcus aureus infection. Clin Infect Dis 43:953-60

7. Fox LP, Geyer AS, Grossman ME (2004) Pyomyositis. J Am Acad Dermatol 51:308-314

Fig. 2 CT of leg showing a large fluid collection (arrows) 